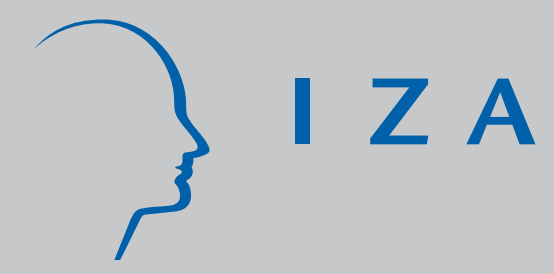

IZA DP No. 1506

Collective Female Labour Supply:

Theory and Application

Olivier Donni

March 2005 


\title{
Collective Female Labour Supply: Theory and Application
}

\author{
Olivier Donni \\ University of Cergy-Pontoise, THEMA, \\ CIRPEE and IZA Bonn
}

\section{Discussion Paper No. 1506 \\ March 2005}

\author{
IZA \\ P.O. Box 7240 \\ 53072 Bonn \\ Germany
}

Phone: +49-228-3894-0

Fax: +49-228-3894-180

Email: iza@iza.org

\begin{abstract}
Any opinions expressed here are those of the author(s) and not those of the institute. Research disseminated by IZA may include views on policy, but the institute itself takes no institutional policy positions.
\end{abstract}

The Institute for the Study of Labor (IZA) in Bonn is a local and virtual international research center and a place of communication between science, politics and business. IZA is an independent nonprofit company supported by Deutsche Post World Net. The center is associated with the University of Bonn and offers a stimulating research environment through its research networks, research support, and visitors and doctoral programs. IZA engages in (i) original and internationally competitive research in all fields of labor economics, (ii) development of policy concepts, and (iii) dissemination of research results and concepts to the interested public.

IZA Discussion Papers often represent preliminary work and are circulated to encourage discussion. Citation of such a paper should account for its provisional character. A revised version may be available directly from the author. 


\begin{abstract}

\section{Collective Female Labour Supply: Theory and Application*}

In this paper, we deal with female labour supply in the collective framework. We study married couples and start from the empirical observation that the husband's labour supply is generally fixed at full-time. We then show that, in this case, structural elements of the decision process, such as individual preferences or the rule that determines the intrahousehold distribution of welfare, can be identified if household demand for at least one commodity, together with the wife's labour supply, is observed. These theoretical considerations are followed by an empirical application using French data.
\end{abstract}

JEL Classification: D12, J22

Keywords: collective decisions, female labour supply, commodity demands

\author{
Olivier Donni \\ Département des sciences économiques \\ École des sciences de la gestion \\ Université du Québec à Montréal \\ Case Postale 8888 \\ Succursale Centre-Ville \\ Montréal (Qc) H3C 3P8 \\ Canada \\ Email: donni.olivier@uqam.ca
}

\footnotetext{
* Financial support from the Fonds Québecois de Recherche sur la Société et la Culture is gratefully acknowledged. This paper was partly written when I was working at the Universite Laval, whose hospitality is gratefully acknowledged. Preliminary versions have been presented in Paris, Lille, Québec and Montréal. We thank François Bourguignon, Pierre-André Chiappori, Bernard Fortin, François Gardes, Guy Lacroix, Thierry Magnac and Costas Meghir for useful comments and suggestions. We also thank Bénédicte Sabatier for her research assistance in the data processing. We bear the sole responsibility for any remaining errors.
} 


\section{Introduction}

Traditionally, the household, as a whole, is considered the elementary decision unit; in particular, consumption and labour supply decisions are modelled as though household members were maximizing a unique utility function under a budget constraint. Nevertheless, this so-called 'unitary' approach has been criticized because, as is generally admitted, a household comprising several adult members does not necessarily behave as a single rational agent. ${ }^{1}$

Still another approach is proposed by Chiappori $(1988,1992)$. This author develops a model of labour supply based on a 'collective' representation of household behaviour. In this framework, each person is characterized by specific preferences, and decisions are assumed to result in Pareto-efficient outcomes. Then, if consumption is purely private and agents are egoistic, efficiency has two attractive properties. First, household labour supply functions have to satisfy testable restrictions. Second, if these restrictions are satisfied, some elements of the decision process, such as preferences and the rule that determines the intra-household distribution of welfare, can be retrieved from the observation of the labour supply functions. Moreover, Donni (2003) shows that this theoretical model can be extended to incorporate the possibility of non-participation decisions and nonlinear budget sets. ${ }^{2}$

The collective approach turns out to be profitable, as shown by recent empirical applications. For example, Fortin and Lacroix (1997) closely follow Chiappori's initial framework and find, using Canadian data, that the restrictions implied by the collective setting are not rejected. Chiappori et alii (2002) extend this framework to allow for 'distribution factors', defined as being any variable that is exogenous with respect to preferences but may influence the decision process. Using the PSID and choosing the sex ratio and an indicator of divorce legislation as distribution factors, they also find that the theoretical restrictions are not rejected.

Unfortunately, these empirical investigations do not account for the fact that, in the majority of developed countries, male labour supply is rigid and largely determined by exogenous constraints. This is a serious problem that was recently addressed by Blundell et alii (2001). These authors examine

\footnotetext{
${ }^{1}$ In addition, the specific restrictions imposed by the unitary model have received little empirical support, if any. See Lundberg and Pollak (1996) on this point.

${ }^{2}$ Fong and Zhang (2001) study a collective model of labour supply where there are two distinct types of leisure: one type of leisure can be seen as 'private' and the other type as 'public'. See Vermeulen (2002) for a survey of collective models.
} 
United Kingdom data from 1978 to 1993 and remark that, when men work, they nearly always work full-time, while wive's hours of work, on the contrary, vary widely. The theoretical model they develop allows for these essential features: the wife's labour supply is assumed to be continuous whereas the husband's choices are assumed to be discrete (either working full time or not at all). They show that the main conclusions, derived by Chiappori in the initial context, are still valid here. One drawback, however, is that such a difference in spouses' behaviour is completely unexplained. Moreover, the result of identifiability and testability given by Blundell et alii (2001) holds only if the husband's choice between working full time and not working is free. In particular, it could be seriously misleading if the husband's unemployment, which is due to demand-side constraints, is mistakenly interpreted in empirical studies as a decision to not participate in the labour market. As a matter of fact, the model of Blundell et alii (2001) is probably convenient when the labour market is very competitive since, in this case, a large proportion of non-working men can be explained by free decisions. Nonetheless, the pertinence of this model to the study of female labour supply is certainly more questionable when the labour market is very regulated.

Our objective in this paper is to investigate female labour supply in France, where a high proportion of unemployment in the population can be seen, in all likelihood, as involuntary. ${ }^{3}$ To do that, we have to handle the rigidity of the husband's behaviour in a quite different way. Our starting point follows Blundell et alii (2001), though. We admit the empirical fact that, for the majority of households, the husband's hours of work are fixed at full-time while the wife's hours of work are spread between zero and the full-time bound. This is at least a good approximation. Now, our approach differs from Blundell et alii (2001), in that the few husbands who do not work are seen as being constrained by involuntary unemployment. In that case, the large proportion of husbands who work full-time can simply be explained by their preferences between leisure and consumption. The crucial point, then, is that the husband's hours of work, if they do not vary or if they are determined by demand-side constraints, tell us nothing about the decision process or preferences. Consequently, the results given by Chiappori (1988, 1992) or Blundell et alii (2001) are no longer valid in the present context.

\footnotetext{
${ }^{3}$ See Laroque and Salanié (2002) for a recent investigation of the role of the minimum wage, together with welfare benefits, in explaining unemployment in France. They stress that the actual cost of the minimum wage to the employer is particularly high in France.
} 
To deal with that, we adopt an alternative approach that is inspired by the literature on collective models of consumption ${ }^{4}$ and, to simplify matters, we ignore the case of households with unemployed husbands. That is to say, our theoretical model focusses on households with husbands working full timethe most common situation - and considers the observation of wive's labour supply, together with information given by the structure of household consumption, to identify the most important elements of the decision process and understand how wive's hours of work are determined.

The next steps are then as follows. First, we extend to collective models the theory of household behaviour under rationing, previously developed by Neary and Roberts (1980) for the unitary approach. This is necessary for studying household behaviour when the labour supply of one spouse is fixed at zero or full-time. Second, assuming that the husband's labour supply is fixed, we demonstrate that the main properties of Chiappori's initial model are preserved. In particular, some elements of the intra-household decision process can be identified from the observation of the wife's labour supply function and on one commodity demand function. ${ }^{5}$ Third, using a technique based on Blundell et alii (2001) and Donni (2003), we prove that this model is still identifiable and testable if the wife does not work. This theoretical advance is empirically relevant since it is generally observed that a large number of women do not participate in the labour market. The final contribution of this paper is to estimate and test this model using French data for couples in which only the husband is working full-time. In this empirical exploration, we take into account the possibility of non-participation of the wife and estimate a five-equation system (one labour supply and four commodity demands).

This paper is structured as follows. Section 2 discusses the assumptions of our framework and Section 3 presents the main theoretical results. Section 4 provides an analysis of our econometric strategy and Section 5 gives a brief description of the data and the empirical results. Section 6 concludes.

\footnotetext{
${ }^{4}$ The main result of this literature is that the intra-household distribution of resources can be retrieved from the observation of a system of commodity demand functions. See Bourguignon et alii (1995) and Chiappori and Ekeland (2002a, 2002b) for the theory, and Browning et alii (1994) and Browning and Chiappori (1998) for empirical applications.

${ }^{5}$ A related result was already mentioned in Bourguignon et alii (1995) in the context of demand analysis with constant prices. The identification result that we present in this paper is more general, however, since the price of the wife's leisure is assumed to be variable.
} 


\section{The Collective Approach}

\subsection{General Framework}

We consider only the case of married couples $(m$ and $f$ ) in a single period setting. ${ }^{6}$ The wife's and husband's labour supply are respectively denoted by $L^{f}$ and $L^{m}$ with market wages $w_{f}$ and $w_{m}$. The wife's and husband's demand for commodity $n(n=1, \ldots, N$, with $N \geqslant 2)$ are respectively denoted by $Q^{f n}$ and $Q^{m n}$ with prices set to one. Non-labour income is denoted by $y$. For convenience, each spouse's total time endowment is normalized at one ${ }^{7}$ and we say that member $i(i=m, f)$ works full-time if $L^{i}=1$. Let $\mathbf{Q}^{i}=$ $\left(Q^{i 1}, \ldots, Q^{i N}\right)$ be the vector of member $i$ 's consumptions. We adopt the following assumption on preferences.

Assumption A1 Each household member is characterized by specific preferences. These can be represented by utility functions of the form: $u^{i}(1-$ $\left.L^{i}, \mathbf{Q}^{i}\right)$ that are both strongly concave, infinitely differentiable and strictly increasing in all their arguments, with $\lim _{Q^{i n} \rightarrow 0} u^{i}\left(1-L^{i}, \mathbf{Q}^{i}\right)=-\infty$.

The household members are said to be 'egoistic' in the sense that their utility only depends on their own consumption and leisure. However, all the results immediately extend to the case of 'caring' agents, with utilities represented by the form:

$$
W_{i}\left[u^{m}\left(1-L^{m}, \mathbf{Q}^{m}\right), u^{f}\left(1-L^{f}, \mathbf{Q}^{f}\right)\right],
$$

where $W_{i}(\cdot)$ is a strictly increasing function; see Chiappori (1992) on this point. Finally, let us note that the condition on limits in A1 lets us rule out cases in which individual consumption is equal to zero.

We implicitly assume that there is no public consumption and no domestic production. The budget set is then written as follows:

$$
\begin{aligned}
& y+L^{f} w_{f}+L^{m} w_{m} \geqslant \sum_{n=1}^{N}\left(Q^{f n}+Q^{m n}\right), \\
& 1 \geqslant L^{i} \geqslant 0 \quad \text { and } \quad Q^{i n} \geqslant 0 \quad(n=1, \ldots, N \text { and } i=f, m) .
\end{aligned}
$$

\footnotetext{
${ }^{6}$ Of course, the fact that the household members are married is not important. The terminology is just for convenience.

${ }^{7}$ This upper bound for hours of work can alternatively be seen as a legal or socio-cultural norm. At this stage, we do not favour any particular interpretation.
} 
We observe that, in surveys, consumption is generally recorded at the household level. We thus assume, in what follows, that only the vector of aggregate consumptions, $\mathbf{Q}=\mathbf{Q}^{f}+\mathbf{Q}^{m}$, is observed by the econometrician.

The main originality of the efficiency approach lies in the fact that household decisions result in Pareto-efficient outcomes and that no additional assumptions are made about the process. This is formally expressed in the following assumption.

Assumption A2 The outcome of the decision process is Pareto efficient; that is, for any wage-income bundle $\left(w_{f}, w_{m}, y\right)$, the labour-consumption bundle $\left(L^{f}, L^{m}, \mathbf{Q}^{f}, \mathbf{Q}^{m}\right)$ chosen by the household is such that no other bundle $\left(\bar{L}^{f}, \bar{L}^{m}, \overline{\mathbf{Q}}^{f}, \overline{\mathbf{Q}}^{m}\right)$ in the budget set could make both members better off.

This assumption has a good deal of intuitive appeal. The household is one of the preeminent examples of a repeated game. Thus, given symmetry of information, it is plausible that agents find mechanisms to support efficient outcomes since cooperation often emerges as a long-term equilibrium of repeated noncooperative relations.

In this theoretical discussion, we suppose that there is no involuntary unemployment. Then, Pareto-efficiency essentially means that there exists a scalar $\mu$ such that household behaviour can be described as a solution to following program:

$$
\max _{\left\{L^{f}, L^{m}, \mathbf{Q}^{f}, \mathbf{Q}^{m}\right\}}(1-\mu) \cdot u^{f}\left(1-L^{f}, \mathbf{Q}^{f}\right)+\mu \cdot u^{m}\left(1-L^{m}, \mathbf{Q}^{m}\right)
$$

with respect to budget sets (1) and (2). The parameter $\mu$ has an obvious interpretation as a 'distribution of power' index. If $\mu=0$, then the household behaves as though the wife always gets her way, whereas if $\mu=1$, the husband is the effective dictator. Moreover, to obtain well-behaved labour supply and commodity demand functions, we assume that the scalar $\mu \in] 0,1[$ is a singlevalued and infinitely differentiable function of $w_{f}, w_{m}$ and $y$. The underlying idea is that, within a bargaining context, the threat point is expected to depend on non-labour income and the wage that the spouses receive when they work.

\subsection{Decentralization and Rationing}

To begin with, we say that a pair of labour supply functions, $L^{f}\left(w_{f}, w_{m}, y\right)$ and $L^{m}\left(w_{f}, w_{m}, y\right)$, together with a pair of systems of commodity demand 
functions, $\mathbf{Q}^{f}\left(w_{f}, w_{m}, y\right)$ and $\mathbf{Q}^{m}\left(w_{f}, w_{m}, y\right)$, are consistent with Collective Rationality $(\mathrm{CR})$ if, for any $\left(w_{f}, w_{m}, y\right) \in \mathbb{R}_{++}^{2} \times \mathbb{R}$, they can be seen as a solution to Programme $\overline{\mathrm{P}}$.

The next step is to introduce the so-called sharing rule. To do this, we use the following lemma.

Lemma 1 A pair of labour supply functions, $L^{f}\left(w_{f}, w_{m}, y\right)$ and $L^{m}\left(w_{f}, w_{m}\right.$, $y)$, together with a pair of systems of $N$ commodity demand functions, $\mathbf{Q}^{f}\left(w_{f}\right.$, $\left.w_{m}, y\right)$ and $\mathbf{Q}^{m}\left(w_{f}, w_{m}, y\right)$, are consistent with $C R$ if and only if there exists a pair of functions, $\rho_{f}\left(w_{f}, w_{m}, y\right)$ and $\rho_{m}\left(w_{f}, w_{m}, y\right)$, with $\sum \rho_{i}=y$, such that $\left[L^{i}\left(w_{f}, w_{m}, y\right), \mathbf{Q}^{i}\left(w_{f}, w_{m}, y\right)\right]$ is a solution to

$$
\begin{array}{r}
\max _{\left\{L^{i}, \mathbf{Q}^{i}\right\}} u^{i}\left(1-L^{i}, \mathbf{Q}^{i}\right) \quad \text { subject to } \quad \sum_{n=1}^{N} Q^{i n}=\rho_{i}+L^{i} \cdot w_{i} \\
\text { and } 1 \geqslant L^{i} \geqslant 0, \quad Q^{i n} \geqslant 0,
\end{array}
$$

for any $\left(w_{f}, w_{m}, y\right) \in \mathbb{R}_{++}^{2} \times \mathbb{R}$.

Proof. This is a straightforward application of the First and the Second Theorems of Welfare Economics. See Bourguignon et alii (1995) for example.\|

This lemma determines the functional structure of labour supply and commodity demand functions. For an interior solution, we have:

$$
\begin{aligned}
L^{f}\left(w_{f}, w_{m}, y\right) & =\lambda^{f}\left(w_{f}, \rho\right), \\
L^{m}\left(w_{f}, w_{m}, y\right) & =\lambda^{m}\left(w_{m}, y-\rho\right),
\end{aligned}
$$

and

$$
Q^{n}\left(w_{f}, w_{m}, y\right)=\zeta^{f n}\left(w_{f}, \rho\right)+\zeta^{m n}\left(w_{m}, y-\rho\right)
$$

where $\rho=\rho_{f}$ and $y-\rho=\rho_{m}$. The functions $\lambda^{f}, \lambda^{m}, \zeta^{f n}$ and $\zeta^{m n}$ are traditional Marshallian labour supply and commodity demand functions. Specifically, the labour supply functions satisfy Slutsky Positivity: $\lambda_{w_{i}}^{i}-\lambda_{\rho_{i}}^{i} L^{i}>0 .{ }^{8}$ The wife's share $\rho$ is then called 'sharing rule'. The latter is generally a function of all the exogenous variables.

\footnotetext{
${ }^{8}$ In what follows, the notation $F_{x}$ stands for the partial differential of function $F$ with respect to variable $x$
} 
For handling corner solutions, we must develop a 'collective' theory of household behaviour under rationing. ${ }^{9}$ We follow the procedure used by Neary and Roberts (1980) for standard systems of demand functions. When the wife is rationed on the labour market, her actual wage is replaced in commodity demand functions by a shadow wage $\omega_{f}$, implicitly defined by

$$
\lambda^{f}\left[\omega_{f}, \rho_{f}+\delta^{f} \cdot\left(w_{f}-\omega_{f}\right)\right]=\delta^{f} \Leftrightarrow \omega_{f}=\omega_{f}\left(\delta^{f} w_{f}+\rho_{f}, \delta^{f}\right),
$$

where $\delta^{f}$ is the level of rationing (equal to zero or one in our model). Thus, the $n$th commodity demand function becomes:

$$
\begin{aligned}
Q^{n}\left(w_{f}, w_{m}, y\right) & =\zeta^{f n}\left[\omega_{f}, \delta^{f} \cdot\left(w_{f}-\omega_{f}\right)+\rho_{f}\right]+\zeta^{m n}\left(w_{m}, \rho_{m}\right) \\
& =\zeta_{\star}^{f n}\left(\delta^{f} w_{f}+\rho, \delta^{f}\right)+\zeta^{m n}\left(w_{m}, y-\rho\right),
\end{aligned}
$$

where the definition (6) is used in the second line and $\zeta_{\star}^{f n}$ is a 'conditional' commodity demand function in the meaning of Browning and Meghir (1991). In words, in the case of rationing, an increase in the wife's wage only has an income effect on household consumption. That means that rationing, as in the unitary framework, causes regime switches in commodity demand functions.

We also have the following cases. First, when the husband is rationed on the labour market, the $n$th commodity demand function becomes:

$$
Q^{n}\left(w_{f}, w_{m}, y\right)=\zeta^{f n}\left(w_{f}, \rho\right)+\zeta_{\star}^{m n}\left(y+\delta^{m} w_{m}-\rho, \delta^{m}\right) .
$$

Second, when both spouses are rationed on the labour market, the $n$th commodity demand function becomes:

$$
Q^{n}\left(w_{f}, w_{m}, y\right)=\zeta_{\star}^{f n}\left(w_{f}^{f} \delta+\rho, \delta^{f}\right)+\zeta_{\star}^{m n}\left(y+\delta^{m} w_{m}-\rho, \delta^{m}\right) .
$$

In this case, we obtain the model of pure consumption studied, in particular, by Bourguignon et alii (1995).

\footnotetext{
${ }^{9}$ This theory is appropriate for dealing with the rationing which stems from corner solutions. The rationing due to involuntary unemployment raises new theoretical issues. We must take into account the fact that individuals in the household are expected to suffer a diminution in bargaining power when they lose their jobs. This provides an interesting direction for future research, though.
} 


\section{Collective Female Labour Supply}

\subsection{Preliminary Considerations}

In the collective model of labour supply, initially developed by Chiappori (1988, 1992), the solutions to Programme $\overline{\mathrm{P}}$ are assumed to be interior. Specifically, it is implicitly assumed that $\left(w_{f}, w_{m}, y\right) \in R$, where $R$ is defined by

$$
R \equiv\left\{\left(w_{f}, w_{m}, y\right) \in \mathbb{R}_{++}^{2} \times \mathbb{R} \mid 1>L^{i}\left(w_{f}, w_{m}, y\right)>0, i=f, m\right\} .
$$

Such a framework, where labour supplies are characterized by (3) and (4), allows us to recover preferences and the outcome of the decision process from the observation of labour supply functions.

In some countries, however, the assumption that both labour supplies freely vary is not appropriate. We often observe, as indicated in the introduction, that the husband's labour supply is fixed at the current upper bound (i.e., $L^{m}=1$ ) for the majority of households and equal to zero for a minority of them. Our framework is hardly consistent with this empirical fact, unless we assume that the husband's unemployment we observe is due to demand-side constraints. This is the idea underlying our approach. We now proceed as follows. First of all, in keeping with the previous section, we focus on the behaviour of households which are not affected by unemployment. Then, we admit that, for unknown reasons, the husband has little taste for leisure and/or is able to obtain a high market wage. This implies, in our setting, that he always chooses the maximum number of hours at his disposal. Formally, assume that $\left(w_{f}, w_{m}, y\right) \in P$, where $P$ is defined by

$$
P \equiv\left\{\left(w_{f}, w_{m}, y\right) \in \mathbb{R}_{++}^{2} \times \mathbb{R} \mid 1>L^{f}\left(w_{f}, w_{m}, y\right)>0, L^{m}\left(w_{f}, w_{m}, y\right)=1\right\}
$$

In other words, the theoretical model that follows analyses the household members' desired hours of work, between zero and one, but supposes that the husband always chooses the maximum number of hours available. ${ }^{10}$

One noteworthy point is that, if $\left(w_{f}, w_{m}, y\right) \in P$, the observation of the sole labour supply functions does not allow us to test efficiency or identify

\footnotetext{
${ }^{10}$ This maximum is assumed the same for all workers. Of course, this line of argument is valid only if 'overtime' hours are not possible.
} 
useful structural elements of the model. ${ }^{11}$ In fact, the observation of the husband's labour supply function does not contain useful information. The idea of this paper is then to use the observation of the structure of consumption to identify the sharing rule and derive testable restrictions.

\subsection{Identifying the Sharing Rule}

First, we assume that only one commodity demand function, together with the wife's labour supply function, is observed. We recall that when the husband's labour supply is fixed at one, these functions are written as:

$$
\begin{aligned}
& L^{f}\left(w_{f}, w_{m}, y\right)=\lambda^{f}\left(w_{f}, \rho\right), \\
& Q^{n}\left(w_{f}, w_{m}, y\right)=\zeta^{f n}\left(w_{f}, \rho\right)+\zeta_{\star}^{m n}\left(y+w_{m}-\rho, 1\right),
\end{aligned}
$$

where the sum of non-labour income and the husband's wage is the 'exogenous' household income. Moreover, under our assumptions, $L^{f}\left(w_{f}, w_{m}, y\right)$ and $Q^{n}\left(w_{f}, w_{m}, y\right)$ as well as $\rho\left(w_{f}, w_{m}, y\right)$ are infinitely differentiable in all their arguments on $\operatorname{int}(P)$. To simplify derivation of the results, we now introduce the following definitions:

$$
\alpha^{n}=\frac{Q_{y}^{n} L_{w_{m}}^{f}-L_{y}^{f} Q_{w_{m}}^{n}}{L_{w_{m}}^{f}-L_{y}^{f}} \quad \text { and } \quad \beta^{n}=\frac{L_{w_{m}}^{f}-L_{y}^{f}}{\alpha_{y}^{n} L_{w_{m}}^{f}-\alpha_{w_{m}}^{n} L_{y}^{f}},{ }^{12}
$$

if $L_{w_{m}}^{f} \neq L_{y}^{f}$ and $\alpha_{y}^{n} L_{w_{m}}^{f} \neq \alpha_{w_{m}}^{n} L_{y}^{f}$. We also assume that the functions we consider satisfy the following regularity conditions.

Assumption R1 The wife's labour supply function and the $n$th commodity demand function are such that $L_{w_{m}}^{f} \neq L_{y}^{f}, \alpha_{w_{m}}^{n} \neq \alpha_{y}^{n}$ and $\alpha_{y}^{n} L_{w_{m}}^{f} \neq \alpha_{w_{m}}^{n} L_{y}^{f}$ for any $\left(w_{f}, w_{m}, y\right) \in \operatorname{int}(P)$.

The first condition obviously implies the absence of income pooling in the wife's labour supply, i.e., the impact of the husband's wage and of nonlabour income on the wife's labour supply are different. The other conditions are more complicated and not examined here. Quite importantly, however,

\footnotetext{
${ }^{11} \mathrm{On}$ the contrary, in the unitary approach, we have testable constraints on the wife's labour supply function even if the husband's labour supply does not vary (e.g., Income Pooling and Slutsky Positivity). Furthermore, 'household' preferences between the wife's leisure and consumption can then be identified from observation of the wife's labour supply.
} 
it can be shown that these conditions exclude the demand function for the 'composite' commodity $Z$ (say) which is defined by $Z=\sum_{n=1}^{N}\left(Q^{f n}+Q^{m n}\right)$.

We can now put forward the next result, which says that some elements of the wife's preferences and the sharing rule can be retrieved.

Proposition 2 Let us assume $C R$. The functions $L^{f}\left(w_{f}, w_{m}, y\right)$ and $Q^{n}\left(w_{f}\right.$, $\left.w_{m}, y\right)$ are observed. Then, under $R 1$, the sharing rule can be retrieved on $P$ up to a constant $\epsilon$. Specifically, its derivatives on int $(P)$ are given by

$$
\rho_{w_{f}}=-\alpha_{w_{f}}^{n} \beta^{n}, \quad \rho_{w_{m}}=1-\alpha_{w_{m}}^{n} \beta^{n} \quad \text { and } \quad \rho_{y}=1-\alpha_{y}^{n} \beta^{n} .
$$

Moreover, for each choice of $\epsilon$, the wife's preferences between total consumption and leisure are uniquely defined. Finally, the individual nth commodity demand function can also be recovered up to a constant $\epsilon^{n}$.

Proof. See the Appendix.\|

We briefly sketch the basic steps of the proof. The idea is that changes in either non-labour income or the husband's wage can only affect the wife's labour supply insofar as her share of exogenous income, as defined by the sharing rule, is modified. This means that any simultaneous change in nonlabour income and the husband's wage that leaves the wife's labour supply unchanged must keep her share constant as well. From this idea, it is possible to measure the effect of exogenous income on commodity demand, keeping the wife's share unchanged. This yields the husband's Engel curve, which in turn allows us to derive other structural elements, like the sharing rule, by differentiation of the Engel curve and resolution of the resulting system of partial differential equations.

\subsection{Testing Collective Rationality}

The next result gives a set of testable restrictions that the wife's labour supply function and the $n$th commodity demand function must satisfy.

Proposition 3 Let us assume CR. The functions $L^{f}\left(w_{f}, w_{m}, y\right)$ and $Q^{n}\left(w_{f}\right.$, $\left.w_{m}, y\right)$ are observed. Then, under $R 1$,

$$
\begin{aligned}
& \text { 1) } \quad L_{w_{f}}^{f}-\frac{L_{w_{m}}^{f}-L_{y}^{f}}{\left(\alpha_{w_{m}}^{n}-\alpha_{y}^{n}\right) \cdot \beta^{n}}\left(L^{f}-\alpha_{w_{f}}^{n} \cdot \beta^{n}\right)>0, \\
& \text { 2) } \quad \alpha_{w_{f}}^{n} \beta_{w_{m}}^{n}=\alpha_{w_{m}}^{n} \beta_{w_{f}}^{n} \quad \text { and } \quad \alpha_{w_{f}}^{n} \beta_{y}^{n}=\alpha_{y}^{n} \beta_{w_{f}}^{n},
\end{aligned}
$$

for any $\left(w_{f}, w_{m}, y\right) \in \operatorname{int}(P)$. 
Proof. See the Appendix.\|

These restrictions provide a joint test of collective rationality under specific assumptions, namely, egoistic (or caring) agents and the absence of public consumption and domestic production. The first condition corresponds to Slutsky Positivity translated in the collective approach. The second condition results from the separability property of the behavioural functions: the husband's wage and non-labour income affect household behaviour only through the individual shares.

More can be obtained when the demand for several commodities, rather than a single one, is observed. This is formally expressed in the following proposition.

Proposition 4 Let us assume CR. The functions $L^{f}\left(w_{f}, w_{m}, y\right), Q^{n_{1}}\left(w_{f}\right.$, $\left.w_{m}, y\right)$ and $Q^{n_{2}}\left(w_{f}, w_{m}, y\right)$ are observed. Then, under $R 1$,

$$
\alpha_{w_{f}}^{n_{1}} \cdot \alpha_{w_{m}}^{n_{2}}=\alpha_{w_{f}}^{n_{2}} \cdot \alpha_{w_{m}}^{n_{1}} \quad \text { and } \quad \alpha_{w_{f}}^{n_{1}} \cdot \alpha_{y}^{n_{2}}=\alpha_{w_{f}}^{n_{2}} \cdot \alpha_{y}^{n_{1}},
$$

for any $\left(w_{f}, w_{m}, y\right) \in \operatorname{int}(P)$.

Proof. See the Appendix.\|

The difference with the case of only one commodity is that the constraints here are based on a second, rather than a third order partial differential equation, which is more restrictive.

\subsection{Extension: The Wife's Rationing}

One of the main limitations of the preceding results is the assumption that the wife is always free to vary the hours she works. Indeed, many wives choose not to work at all or to work full-time, two cases ruled out in the earlier discussion. In this section, we thus consider the wife's participation decision. The results can easily be extended to the converse case of working full-time, though.

First, we note that the existence of a well-behaved participation frontier does not stem from the theoretical construct as in standard labour supply 
models, but must be postulated. ${ }^{13}$ Therefore, we use the following assumption.

Assumption R2 There exists a positive function $\gamma\left(w_{m}, y\right)$ defined on $\mathbb{R}_{++}$ $\times \mathbb{R}$ such that the wife does not participate in the labour market if and only if $w_{f} \leqslant \gamma\left(w_{m}, y\right)$.

We also assume that the wife's market wage $w_{f}$ is observed even when she does not work. Of course, this is very restrictive but, in practice, the market wage can be estimated by an auxiliary equation. ${ }^{14}$ We thus suppose that $\left(w_{f}, w_{m}, y\right) \in N$ where $N$ is defined by

$$
N \equiv\left\{\left(w_{f}, w_{m}, y\right) \in \mathbb{R}_{++}^{2} \times \mathbb{R} \mid L^{f}\left(w_{f}, w_{m}, y\right)=0, L^{m}\left(w_{f}, w_{m}, y\right)=1\right\} .
$$

We also define $I \equiv\left\{\left(w_{m}, y\right) \mid\left(w_{f}, w_{m}, y\right) \in N\right.$ and $\left.w_{f}=\gamma\left(w_{m}, y\right)\right\}$. In Figure 1, the sets $P, N$ and $I$ are illustrated in a two-dimensional plane (i.e., for a fixed $y$ ). We see, in this figure, that the wife does not work when her wage is below its reservation value (given by the curve in bold) and she works fulltime when her wage is above some critical value (given by the upper curve). ${ }^{15}$ We can say the same for the husband.

We finally assume that we observe the $n$th commodity demand function, given by

$$
Q^{n}\left(w_{f}, w_{m}, y\right)=\zeta_{\star}^{f n}(\rho, 0)+\zeta_{\star}^{m n}\left(y+w_{m}-\rho, 1\right)
$$

and the participation frontier, defined as $w_{f}=\gamma\left(w_{m}, y\right)$. Under our assumptions, this commodity demand function and the participation frontier are infinitely differentiable on $\operatorname{int}(N)$ and $I$, respectively. Moreover, along the participation frontier, the $n$th commodity demand function can be written as follows:

$$
\hat{Q}^{n}\left(w_{m}, y\right)=Q^{n}\left[\gamma\left(w_{m}, y\right), w_{m}, y\right] .
$$

\footnotetext{
${ }^{13}$ The idea is that, when the wife is indifferent between working and not working, a small increase in her wage has a substitution effect - as in the standard model - but also an income effect through the sharing rule. The former is necessarily positive but the latter can be positive or negative. See Blundell et alii (2001) and Donni (2003) for a formal discussion.

${ }^{14}$ Still, the treatment of this issue may raise very complicated problems which are not addressed here. See Blundell et alii (2001) for a first investigation.

${ }^{15}$ The wife's (husband's) labour supply, if it is backward bending, may fall below 1 for some wages which are particularly high, but this feature is not represented in Figure 1.
} 


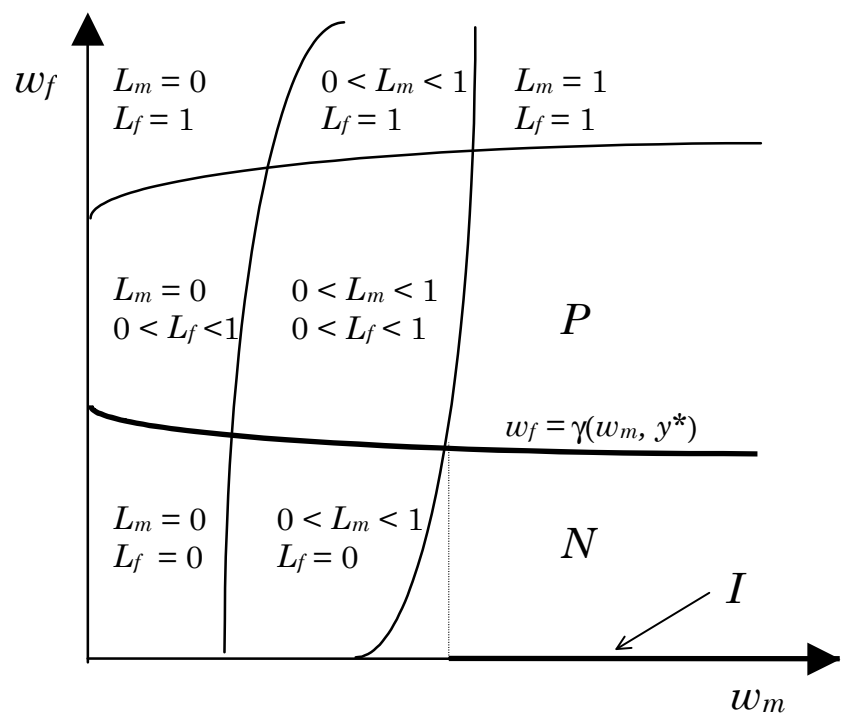

Figure 1: A Two-dimensional Illustration of Rationing Sets (with $y=$ constant)

The latter is infinitely differentiable on $I$. The next step is to define the following functions:

$$
A^{n}=\frac{\hat{Q}_{y}^{n} \gamma_{w_{m}}-\gamma_{y} \hat{Q}_{w_{m}}^{n}}{\gamma_{w_{m}}-\gamma_{y}} \text { and } \quad B^{n}=\frac{\gamma_{w_{m}}-\gamma_{y}}{\gamma_{w_{m}} A_{y}^{n}-\gamma_{y} A_{w_{m}}^{n}},
$$

if $\gamma_{w_{m}} \neq \gamma_{y}$ and $\gamma_{w_{m}} A_{y}^{n} \neq \gamma_{y} A_{w_{m}}^{n}$, and introduce the following regularity condition.

Assumption R3 The wife's participation frontier and the $n$th commodity demand are such that $\gamma_{w_{m}} \neq \gamma_{y}, A_{w_{m}}^{n} \neq A_{y}^{n}, \gamma_{w_{m}} A_{y}^{n} \neq \gamma_{y} A_{w_{m}}^{n}$ and $\hat{C}_{w_{m}}^{n} \neq \hat{C}_{y}^{n}$ for any $\left(w_{m}, y\right) \in I$.

The next result says, first, that the sharing rule can be retrieved on $N$ up to a constant and, second, that testable restrictions are generated.

Proposition 5 Let us assume $C R$. The functions $\gamma\left(w_{m}, y\right)$ and $Q^{n}\left(w_{f}, w_{m}\right.$, $y)$ are observed. Then, under R2 and R3, the sharing rule can be retrieved on 
$N$ up to a constant $\epsilon$. Specifically, let $v\left(w_{m}, y\right)=\rho\left[\gamma\left(w_{m}, y\right), w_{m}, y\right]$. Then, the derivatives of $v\left(w_{m}, y\right)$ on $I$ are given by

$$
v_{w_{m}}=1-A_{w_{m}}^{n} B^{n} \quad \text { and } \quad v_{y}=1-A_{y}^{n} B^{n} .
$$

Moreover, the individual nth commodity demand can be retrieved up to a constant $\epsilon^{n}$. Finally, we have the following constraint:

$$
A_{y}^{n} B_{w_{m}}^{n}=A_{w_{m}}^{n} B_{y}^{n}
$$

for any $\left(w_{m}, y\right) \in I$.

Proof. See the Appendix.

At this stage, some clarifications are necessary. First, the proof of this proposition does not require complete specification of the wife's underlying labour supply, but only of the participation frontier. This result is useful since surveys generally contain information about the employment status of household members but not necessarily about the number of hours of work. The wife's wage must be observed, though. Second, considering additional commodity demands obviously creates new constraints. These are not formally examined in this paper. In fact, commodity demand functions with 'double rationing' receive great attention in Bourguignon et alii (1995). In particular, these authors show that a triplet of commodity demand functions is sufficient to identify the sharing rule. By comparison, the result above requires only one commodity demand function and the participation frontier. Finally, the results of Proposition 5 complete those of Proposition 2 and ensure that the sharing rule is identified on the entire set of interest to us, $P \cup N$.

\section{Econometric Analysis}

In this section, we consider empirical implementation of the model described above. First, we propose a functional form for labour supply and the system

of commodity demands. Second, we introduce stochastic terms and derive the log-likelihood function. 


\subsection{Functional Form}

In this section and those that follow, we adopt the following conventions : $w_{f h}$ denotes the wife's hourly wage in household $h, w_{m h}$ the husband's hourly wage, $y_{h}$ monthly non-labour income, $L_{f h}$ the observed number of hours worked per month, $Q_{h}^{n}$ expenditure on commodity $n$ per month, and $T$ the (legal or socio-cultural) maximum number of hours per month.

\subsubsection{Labour Supply and Commodity Demands}

In order to estimate and test this model, we adopt the linear functional form, initially proposed by Hausman (1981), for the wife's latent labour supply. If we ignore the stochastic terms at this stage, we have:

$$
L_{f h}^{*}=\alpha_{h}+\beta w_{f h}+\gamma \rho_{h},
$$

where $L_{f h}^{*}$ is the wife's latent number of worked hours per month. The wife is rationed on the labour market if the latent variable is either greater than $T$ or less than 0 :

$$
\begin{aligned}
& L_{f h}=T \quad \text { if } \quad L_{f h}^{*} \geqslant T, \\
& L_{f h}=0 \text { if } \quad L_{f h}^{*} \leqslant 0, \\
& L_{f h}=L_{f h}^{*} \quad \text { otherwise. }
\end{aligned}
$$

Moreover, the intercept $\alpha_{h}$ is assumed to depend on a set of variables:

$$
\alpha_{h}=\sum_{j=1}^{J} \alpha_{j} \cdot z_{j f h},
$$

where $z_{j f h}$ are socio-demographic characteristics relevant for explaining the wife's behaviour (e.g., the wife's age, the region of residence, the number of children). Finally, Slutsky Positivity is globally fulfilled if and only if $\beta \geqslant \max (0, \gamma T)$.

This specification has several desirable properties. First, the linear form for labour supply has frequently been used in empirical studies and is suitable for French data; see Bourguignon and Magnac (1990) for another application. ${ }^{16}$ Second, the wife's preferences between leisure and consumption have

\footnotetext{
${ }^{16}$ We tested a more flexible functional form by introducing a second-order polynomial in $\rho_{h}$, but the coefficient associated with this term proved to be insignificant. Other specifications (e.g., a logarithmic term for $w_{f h}$ ) were also tried unsuccessfully.
} 
a well-known form; see Hausman (1981). They are described by the following indirect utility function:

$$
V\left(w_{f h}, \rho_{h}\right)=\exp \left(\gamma w_{f h}\right) \cdot\left(\rho_{h}+\frac{\beta}{\gamma} w_{f h}-\frac{\beta}{\gamma^{2}}+\frac{\alpha_{h}}{\gamma}\right)
$$

Third, and more importantly, this specification permits us to have a closed form for shadow wages which are used to compute rationed commodity demand functions. Of course, the main limitation of the linear functional form is its lack of flexibility; in particular, it implies, when Slutsky Positivity is imposed, that the labour supply curve is upward sloping everywhere.

We now consider the functional form of the commodity demands. We assume that, when $0<L_{f h}^{*}<T$, the $n$th commodity demand function is quadratic, ${ }^{17}$ as follows:

$$
\begin{aligned}
Q_{h}^{n}= & a_{f h}^{n}+b_{f}^{n} w_{f h}+c_{f}^{n} \rho_{h}+d_{f}^{n} \rho_{h}{ }^{2}+a_{m h}^{n}+c_{m}^{n}\left(y_{h}+w_{m h} T-\rho_{h}\right) \\
& +d_{m}^{n}\left(y_{h}+w_{m h} T-\rho_{h}\right)^{2} .
\end{aligned}
$$

According to our theory, this functional form switches regimes in the presence of rationing. Two cases must be considered. First, when $L_{f h}^{*} \leqslant 0$, we compute a shadow wage as follows:

$$
\omega_{f h}=-\frac{\alpha_{h}+\gamma \cdot \rho_{h}}{\beta},
$$

and introduce this expression into the $n$th commodity demand to obtain:

$$
\begin{aligned}
Q_{h}^{n}= & a_{f h}^{n}+b_{f}^{n} \omega_{f h}+c_{f}^{n} \rho_{h}+d_{f}^{n} \rho_{h}{ }^{2}+a_{m h}^{n}+c_{m}^{n}\left(y_{h}+w_{m h} T-\rho_{h}\right) \\
& +d_{m}^{n}\left(y_{h}+w_{m h} T-\rho_{h}\right)^{2} .
\end{aligned}
$$

Second, when $L_{f h}^{*} \geqslant T$, the shadow wage becomes:

$$
\omega_{f h}=\frac{T-\alpha_{h}-\gamma \cdot\left(w_{f h} T+\rho_{h}\right)}{\beta-\gamma T},
$$

and we introduce this expression into the $n$th commodity demand. Since this substitution also influences the shadow income, we obtain:

$$
\begin{aligned}
Q_{h}^{n}= & a_{f h}^{n}+b_{f}^{n} \omega_{f h}+c_{f}^{n}\left(\left(w_{f h}-\omega_{f h}\right) T+\rho_{h}\right)+d_{f}^{n}\left(\left(w_{f h}-\omega_{f h}\right) T+\rho_{h}\right)^{2} \\
& +a_{m h}^{n}+c_{m}^{n}\left(y_{h}+w_{m h} T-\rho_{h}\right)+d_{m}^{n}\left(y_{h}+w_{m h} T-\rho_{h}\right)^{2} .
\end{aligned}
$$

\footnotetext{
${ }^{17}$ Using our data, we also experimented with a functional form with a third-order term in $\rho_{h}$ and in $\left(y+w_{h} T-\rho_{h}\right)$, but these terms turn out to be statistically insignificant.
} 
This way of dealing with rationing implies that commodity demand functions are continuous everywhere (in particular, along the frontiers where the regime switches) and an increase in the wife's wage, in the case of rationing, only has an income effect on consumption. Finally, since individual intercepts cannot be both identified, we reset the parameters $a_{h}^{n}=a_{f h}^{n}+a_{m h}^{n}$ with

$$
a_{h}^{n}=\sum_{j=1}^{J} a_{j}^{n} \cdot z_{j h},
$$

where $z_{j h}$ are socio-demographic variables relevant for explaining the spouses' behaviour.

\subsubsection{The Sharing Rule and the Collective Constraints}

As in Fortin and Lacroix (1997) and Blundell et alii (2001), we adopt a linear specification for the sharing rule:

$$
\rho_{h}=A \cdot w_{f h} T+B \cdot w_{m h} T+C \cdot y_{h} .
$$

Although the sign of the parameters is not formally determined by the model above, intuition suggests that

$$
0<B<C<1 \text {. }
$$

However, the coefficient $A$ can be either positive or negative since its sign results from two opposite effects; see Chiappori (1992). To show that, let us assume that the wife's wage rises. If she works, the income of the household, as a whole, should increase and both members should benefit from that. At the same time, however, the wife improves her bargaining power. This last effect should have a negative impact on the husband's share. All in all, the negative impact of the wife's wage on the husband's share likely predominates if the welfare gains resulting from the wage increase are small enough (notably if the wife does not work). ${ }^{18}$ Specifically, if we introduce the sharing rule (12) into the utility function (11), differentiate with respect to $w_{f h}$, and use (10), we can demonstrate that the wife benefits from an increase in her wage only if

$$
A+\frac{L_{f h}}{T}>0
$$

\footnotetext{
${ }^{18}$ In principle, these two effects could be modelled by assuming that the sharing rule switches regimes in the case of rationing. There is, however, a potential problem of logical consistency if the sharing rule is assumed to be a function of the wife's observed hours of work.
} 
This condition may be satisfied when $A$ is negative, if $L_{f h}$ is large enough.

To test collective rationality, we must derive the unconstrained model that corresponds to the present specification. To do that, we adopt the approach followed by Browning et alii (1994). The crucial point here is that there is an equivalence between collective rationality and the existence of a single sharing rule in all the equations (as stated by Lemma 1). Moreover, at least one commodity demand function, together with the wife's labour supply function, is required to identify the sharing rule. Let us write the sharing rule as follows:

$$
\rho_{h}=A \cdot w_{f h} T+B \cdot\left(w_{m h} T+\Phi \cdot y_{h}\right)
$$

where $\Phi=C / B$. The idea behind the identification, transposed to this functional form, is that $\Phi$ can be identified from estimation of the wife's labour supply function. Then, knowing $\Phi$, the estimation of one commodity demand function (say $n=1$, without loss of generality) allows one to identify $A$ and $B$. In addition, each extra commodity demand function generates a pair of overidentifying restrictions. ${ }^{19}$ Thus, the strategy for testing collective rationality consists in writing the sharing rule as follows:

$$
\rho_{h}^{n}=A^{n} \cdot w_{f h} T+B^{n} \cdot\left(w_{m h} T+\Phi \cdot y_{h}\right),
$$

for each additional commodity demand, and checking the equalities :

$$
A^{n}=A \quad \text { and } \quad B^{n}=B
$$

for any $n>1$. This comes down to checking that the sharing rule is the same in all the equations.

\subsection{Stochastic Specification and the Likelihood Func- tion}

We have to make some allowance for stochastic terms in the right-hand side of these equations. There are several sources of such randomness: unobservable heterogeneity in preferences or in the sharing rule and optimization/measurement errors in observations. The most satisfactory treatment

\footnotetext{
${ }^{19}$ To be precise, the restrictions given in Proposition 3 are automatically satisfied by our functional form. The test of collective rationality is then based on the conditions given in Proposition 4.
} 
would be to allow for each of these and to develop a full stochastic model (see Blundell et alii (2001) for such an attempt in a less complicated context). However, this would entail the introduction of a large number of stochastic terms and make the model almost intractable. More importantly, the distribution of these terms is not necessarily identifiable. Hence we adopt a much more conventional approach of simply adding error terms to each equation: $v_{h}$ for the wife's labour supply and $\varepsilon_{h}^{n}$ for the $n$th commodity demand.

We assume that the vector $\left(v_{h}, \varepsilon_{h}^{1}, \ldots, \varepsilon_{h}^{N}\right)$ follows a multidimensional normal distribution with mean zero and a covariance matrix given by

$$
\begin{array}{llr}
\Sigma & \text { if } & 0<L_{f h}^{*}<T, \\
\Sigma_{0}=\Gamma_{0} \cdot \Sigma \cdot \Gamma_{0}^{\prime} & \text { if } & L_{f h}^{*} \leqslant 0, \\
\Sigma_{1}=\Gamma_{1} \cdot \Sigma \cdot \Gamma_{1}^{\prime} & \text { if } & L_{f h}^{*} \geqslant T,
\end{array}
$$

where $\Sigma$ is a matrix of free parameters and $\Gamma_{0}$ and $\Gamma_{1}$ are identity matrices with free parameters instead of zeros in the first column. This specification is a convenient approximation when stochastic terms in the wife's labour supply result from a mix of unobservable taste heterogeneity and optimization/measurement errors (it is a straightforward generalization of the approach of Kooreman and Kapteyn (1986) to the case of more than two equations). ${ }^{20}$ This reflects the fact that, in the case of rationing, the taste heterogeneity factor in the wife's labour supply is 'introduced' into commodity demands through shadow wages.

These assumptions, with the relationships defined above, directly yield a distribution on hours of work and commodity quantities. There are three regimes. Wives are either unrationed, rationed at 0 , or rationed at $T$. Let us denote $\underline{R}_{h}=-\alpha_{h}-\beta w_{f h}-\gamma \rho_{h}, \bar{R}_{h}=T-\alpha_{h}-\beta w_{f h}-\gamma \rho_{h}$, and

$$
g:\left(L_{f h}, Q_{h}^{1}, \ldots, Q_{h}^{N}\right) \rightarrow\left(v_{h}, \varepsilon_{h}^{1}, \ldots, \varepsilon_{h}^{N}\right)
$$

the relationship between observations and stochastic terms. The density for wives who are unrationed is given by

$$
\begin{aligned}
f\left(L_{f h}, Q_{h}^{1}, \ldots, Q_{h}^{N}\right) & =\phi_{\Sigma}\left(v_{h}, \varepsilon_{h}^{1}, \ldots, \varepsilon_{h}^{N}\right) \\
& =\phi_{\Sigma}\left[g\left(L_{f h}, Q_{h}^{1}, \ldots, Q_{h}^{N}\right)\right],
\end{aligned}
$$

where $\phi_{\Sigma}$ denotes the multidimensional normal density with a mean of zero and a matrix $\Sigma$ of covariances (the determinant of the Jacobian matrix for

\footnotetext{
${ }^{20}$ The inaccuracy in the distribution of the random terms is the price of our rejection of a full stochastic specification.
} 
the variable transformation is equal to one). Then the contribution to the likelihood for wives who are rationed at 0 is given by

$$
\begin{aligned}
F_{0}\left(Q_{h}^{1}, \ldots, Q_{h}^{N}\right) & =\int_{-\infty}^{\underline{R}_{h}} \phi_{\Sigma_{0}}\left(v_{h}, \varepsilon_{h}^{1}, \ldots, \varepsilon_{h}^{N}\right) \cdot \mathrm{d} v_{h} \\
& =\int_{-\infty}^{0} \phi_{\Sigma_{0}}\left[g\left(L_{f h}^{*}, Q_{h}^{1}, \ldots, Q_{h}^{N}\right)\right] \cdot \mathrm{d} L_{f h}^{*} .
\end{aligned}
$$

Similarly, the contribution for wives who are rationed at $T$ is given by

$$
\begin{aligned}
F_{1}\left(Q_{h}^{1}, \ldots, Q_{h}^{N}\right) & =\int_{\bar{R}_{h}}^{+\infty} \phi_{\Sigma_{1}}\left(v_{h}, \varepsilon_{h}^{1}, \ldots, \varepsilon_{h}^{N}\right) \cdot \mathrm{d} v_{h} \\
& =\int_{T}^{+\infty} \phi_{\Sigma_{1}}\left[g\left(L_{f h}^{*}, Q_{h}^{1}, \ldots, Q_{h}^{N}\right)\right] \cdot \mathrm{d} L_{f h}^{*} .
\end{aligned}
$$

Finally, combining these expressions provides the log-likelihood function of the econometric model:

$$
L\left(L_{f h}, Q_{h}^{1}, \ldots, Q_{h}^{N}\right)=\sum_{L_{f h}=0} \ln F_{0}+\sum_{L_{f h}=T} \ln F_{1}+\sum_{0<L_{f h}<T} \ln f .
$$

A critical assumption in the above analysis concerns the observability of the wage for all wives. This is, of course, not the case for unemployed women. Our approach is thus based on the construction of a fitted value $\hat{w}_{f h}$ for the wage using censored regression techniques and interprets $\hat{w}_{f h}$ as the wage faced by all workers.

\section{$5 \quad$ Data and Empirical Results}

In this section we present the main results. First we describe the data set, then we give the estimated coefficients and the statistics for the test of the collective constraints.

\subsection{The Data}

Data are drawn from the household survey "Budget des Familles" conducted by the national institute of economic and statistical information of France (INSEE) in a sample of 12,000 French households in 1984-85. The survey contains detailed information on earnings and income from property and transfers, on expenditures for nondurable as well as durable commodities, on 
most socio-demographic characteristics of individuals and households and, finally, on the number of hours and the work status of individuals. Several studies have used this survey over the last 10 years, allowing some interesting comparisons to be made. For instance, Bourguignon et alii (1993) use a sample extracted from this survey to test the collective approach in a context of pure consumption. They do not reject the theoretical restrictions.

From the original sample, we first select a subsample of married couples with, at most, one child between 3 and 18 years old. Children, and expenditures on them, may indeed be considered public commodities for both parents, whereas the model considered above only allows for private commodities. Moreover, children are expected to increase problems related to household production. On the other hand, considering only childless couples restricts the size of our sample considerably.

We next restrict the sample to couples in which husband and wife (if they are working) are not self-employed. ${ }^{21}$ These selection rules and the exclusion of observations with missing data leave us with a total of 1078 observations. The distribution of working hours in this sample is described in Table 1. However, according to our theory, the sample we use in the empirical analysis must contain only couples that are not affected by involuntary unemployment and in which the husband works full-time (i.e., arbitrarily defined by monthly labour supply above 140 hours). Hence, we remove 200 extra observations and obtain a final sample of 878 households. ${ }^{22}$ Conditioning the sample on full-time working husbands may, in principle, induce a selectivity bias. However, the number of households in which the husband does not work full-time is small. In addition, it is predominantly made up of job seekers (even if this may hide a voluntary decision) and one may reasonably believe that the problem of selection is less important in this case. In particular, it may be completely negligible if unemployment indiscriminately strikes any household regardless of the wife's and husband's characteristics.

Table 2 reports descriptive statistics of the final sample. The wife's labour supply is the number of hours worked per month. It is computed by multiplying the number of reported weekly hours by 4.2. Expenditures on nondurable commodities are recorded in the survey in diaries covering two-week

\footnotetext{
${ }^{21}$ Some occupations for which the number of worked hours can hardly be measured (scientists, artists, teachers, soldiers and so on) are also excluded from our sample.

${ }^{22} \mathrm{We}$ also remove households with one member whose monthly labour supply is above 220 hours from our sample. This makes up about $5 \%$ of the sample.
} 


\begin{tabular}{lcc}
\hline \hline & Husband & Wife \\
\hline Job Seekers & 65 & 69 \\
Monthly Working Hours & & \\
\hline Equal to 0 (voluntarily) & 1 & 324 \\
Between 1 and 100 & 9 & 59 \\
Between 101 and 140 & 15 & 45 \\
Between 141 and 180 & 806 & 540 \\
Between 181 and 220 & 136 & 29 \\
More than 220 & 46 & 12 \\
\hline Total & 1078 & 1078 \\
\hline \hline
\end{tabular}

Table 1: Distribution of Working Hours in the Intermediate Sample

periods and extrapolated to the year. ${ }^{23}$ In the empirical application, we calculate monthly expenditures on food (at home and away), clothing (for husbands, wives, and children), recreation (including books, disks, vacations and sporting goods) and transportation (excluding purchases of vehicles) respectively. Practically, there may be problems due to the infrequency of purchases. However, this must not be overestimated because the commodities that we consider are aggregated and the lumpiness in these expenditures is minimal.

The wife's hourly wage is computed as the monthly wage net of payroll deductions but including overtime, bonuses, pensions, and a monetary evaluation of benefits in kind, divided by the number of hours worked. This wage is then replaced for all observations by the fitted values derived from a conventional wage equation estimated for participating wives with a correction for selection bias. ${ }^{24}$ The husband's hourly wage is defined in the same way as the wife's hourly wage. Monthly non-labour income includes various transfers and income from different types of assets (including child benefits) and the virtual income of home owner-occupiers, certainly the most important asset return, from which the repayment of debts and mortgages is subtracted. This virtual income is not directly observed but computed as the fitted value of an equation estimated on renting households.

One final point must be stressed. The French labour market is charac-

\footnotetext{
${ }^{23}$ Expenditures on clothing are recorded over a two-month period, but this difference with other nondurables is not taken into account.

${ }^{24}$ The results of this regression are described in Appendix B.
} 


\begin{tabular}{lcccc}
\hline \hline & Mean & St. Dev. & Min & Max \\
\hline \multicolumn{1}{c}{ A. Dependent Variables } & & & \\
\hline Wife's Monthly Hours of Labour (LAB) & 106 & 75 & 0 & 210 \\
Percentage of zeros & 31 & & & \\
Monthly Food Expenditures* (FOO) & 2479 & 1181 & 92 & 11672 \\
$\quad$ Percentage of zeros & 0 & & & \\
Monthly Clothing Expenditures* (CLO) & 683 & 699 & 0 & 5745 \\
$\quad$ Percentage of zeros & 7 & & & \\
Monthly Recreation Expenditures* (REC) & 629 & 715 & 0 & 11084 \\
Percentage of zeros & 1 & & & \\
Monthly Transportation Expenditures* (TRA) & 890 & 979 & 0 & 11630 \\
Percentage of zeros & 6 & & & \\
\hline \multicolumn{1}{c}{ B. Independent Variables } & & & \\
\hline Wife's Hourly Wage (Actual) $\times 160^{*}$ & 5036 & 1726 & 590 & 15692 \\
Wife's Hourly Wage (Predicted) $\times 160^{*}$ & 4747 & 1040 & 2355 & 13328 \\
Husband's Hourly Wage $\times 160^{*}$ & 6822 & 3372 & 2381 & 43549 \\
Monthly Nonlabour Income* & 353 & 1645 & -4591 & 15900 \\
Percentage of zeros & 27 & & & \\
Wife's Age & 39 & 11 & 18 & 64 \\
Husband's Age & 41 & 11 & 20 & 65 \\
Paris Region & 0.16 & 0.37 & 0 & 1 \\
Presence of one child & 0.44 & 0.50 & 0 & 1 \\
\hline Number of observations & 878 & & & \\
\hline \hline
\end{tabular}

Table 2: Descriptive Statistics of the Final Sample (* In French francs) 
terized by extensive regulation of hours of work. Labour laws fix an exogenous norm for companies and the number of overtime hours remains strictly bounded. In 1984-85, this norm was generally equal to 39 hours per week; each hour of work over that figure can be interpreted as overtime (almost all the variability in the husband's labour supply stems from overtime hours, as shown in Table 1). If we multiply 39 hours by 4.2 and round down, we obtain 160 hours per month. This figure is naturally interpreted as the upper bound that the household members face. We thus set $T=160$ in the log-likelihood function. ${ }^{25}$

\subsection{Parameter Estimates}

We include four (three) preference factors in the commodity demands (wife's labour supply); this is the end result of a preliminary analysis which excluded some variables (such as several dummies for the region of residence). Ultimately, we estimated 49 structural parameters; 6 for the wife's labour supply, 10 for each commodity demand, and 3 for the sharing rule. Before beginning our investigation of these estimates, we first check the parametric restrictions implied by collective rationality. To do that, we use the unconstrained model previously derived and compute the statistics for the score test. This statistic, which follows a $\chi^{2}$ distribution with 6 degrees of freedom, is equal to 6.660 with a $p$-value of 0.353 . In other words, the data that we consider do not reject the efficiency hypothesis. This confirms the test previously performed with the same data by Bourguignon et alii (1993).

The estimates are presented in Tables 3 and 4 . We note that only 12 (19) parameters are statistically significant at the $5(10) \%$ level. That is mediocre but can be explained, at least partially, by the small size of our sample. ${ }^{26}$ Fortunately, however, some important parameters are quite precisely estimated. Let us first consider the wife's labour supply. All the coefficients have the expected sign (except, perhaps, the regional dummy), and Slutsky Positivity is globally satisfied. The wage coefficient is significant and positive; its value

\footnotetext{
${ }^{25}$ In doing that, we ignore the information contained in the number of overtime hours. Still, this information is not necessarily reliable because certain jobs do not permit hours of work to exceed the legal norm. In addition, the number of overtime hours is limited to 180 hours per year under French labour law.

${ }^{26}$ In preliminary estimations, we used a larger sample incorporating households with several children. However, the collective restrictions are then rejected with this sample. A similar conclusion was drawn by Fortin and Lacroix (1997).
} 


\begin{tabular}{lccccc}
\hline \hline & LAB & FOO & CLO & REC & TRA \\
\hline Intercept & 222.8 & 302.1 & 285.2 & 36.0 & 360.6 \\
& $(45.5)$ & $(361.0)$ & $(168.3)$ & $(211)$ & $(363.5)$ \\
Wife's Wage & 5.6 & 14.7 & 6.0 & 5.2 & 53.0 \\
& $(1.9)$ & $(6.0)$ & $(3.0)$ & $(3.3)$ & $(18.4)$ \\
Wife's Share $\times$ 1e-3 francs & -90.9 & -80.8 & -143.4 & -80.8 & -387.4 \\
& $(54.6)$ & $(92.0)$ & $(149.5)$ & $(92.0)$ & $(360.0)$ \\
Wife's Share $\times$ 1e-3 francs exp2 & - & -63.3 & -17.3. & 7.5 & -60.7 \\
& & $(83.8)$ & $(32.0)$ & $(27.7)$ & $(85.3)$ \\
Husband's Share $\times$ 1e-3 francs & - & 220.3 & 79.0 & 12.6 & 102.6 \\
& & $(56.7)$ & $(25.1)$ & $(3.0)$ & $(65.3)$ \\
Husband's Share $\times$ 1e-3 francs exp2 & - & -3.4 & -0.8 & -1.7 & -2.5 \\
& & $(2.4)$ & $(1.0)$ & $(1.1)$ & $(2.8)$ \\
\hline \multicolumn{2}{c}{ Socio-demographic } & Variables & & & \\
\hline One Child 4-18 years & -20.3 & 353.8 & -16.45 & 45.6 & 55.2 \\
Paris Region & $(18.6)$ & $(84.2)$ & $(56.0)$ & $(63.4)$ & $(131.4)$ \\
& -49.0 & 166.8 & -65.0 & 139.5 & -589.0 \\
Wife's Age & $(28.9)$ & $(113.4)$ & $(78.8)$ & $(15.8)$ & $(207.0)$ \\
Husband's Age & -6.3 & 1.3 & -11.1 & 0.2 & -27.1 \\
& $(1.0)$ & $(11.7)$ & $(7.3)$ & $(8.5)$ & $(12.7)$ \\
\hline \hline
\end{tabular}

Table 3: FIML Parameter Estimates of the Behavioural Equations (Standard deviations are in brackets.) 


\begin{tabular}{clcc}
\hline \hline & & Estimates & St. Dev \\
\hline$A$ & Wife's Wage $\times 160 \times 1 \mathrm{e}-3$ francs & -0.281 & 0.190 \\
$B$ & Husband's Wage $\times 160 \times 1 \mathrm{e}-3$ francs & 0.122 & 0.081 \\
$C$ & Nonlabour Income $\times 1 \mathrm{e}-3$ francs & 0.392 & 0.219 \\
\hline \multicolumn{4}{c}{ Tests of Income Pooling Hypotheses } \\
\hline$A-B$ & -0.327 & 0.373 \\
$B-C$ & -0.270 & 0.154 \\
$A-C$ & -0.597 & 0.252 \\
\hline \hline
\end{tabular}

Table 4: FIML Parameter Estimates of the Sharing Rule

is compatible with previous studies using French data (e.g., Bourguignon and Magnac (1990)). The share coefficient is negative but not very significant. However, when it is compared with values obtained from standard models of labour supply, it seems excessively large: a one thousand franc increase in the wife's share reduces the wife's labour supply by 90 hours. There are two explanations for this surprising result. Firstly, the collective model (and the interpretation of its parameters) is simply different from the unitary one. More precisely, the explanatory variable in the collective model is a share of exogenous income whereas, in the unitary model, it is all exogenous income. Thus, it is hardly surprising that the estimates are very different from what we generally obtain. Secondly, the number of hours worked is assumed to have an upper bound, fixed at 160. This implies, in particular, that the effect of an increase in the wife's share here is not necessarily 'effective' because she may be constrained at the upper (or the lower) bound. ${ }^{27}$

We do not dwell on the estimated parameters of the commodity demands since these cannot be directly interpreted. Still, it is worth remarking that, in these equations, the parameters for the husband's demands are fairly well estimated (three of them are significant at the $5 \%$ level) in comparison with those for the wife's demands. A possible explanation is suggested in the proof of Proposition 2. In this proof, the identification of the husband's Engel curves is shown to rely on the first derivatives of the functions that are observed. The wife's Engel curves are then derived from the husband's and are based on second-order derivatives. They are expected to be less precisely estimated.

\footnotetext{
${ }^{27}$ As expected, the empirical results (and, above all, the coefficient of the wife's share) turn out to be particularly sensitive to the selection of the upper bound.
} 
As for the control variables, let us note that the child dummy is significant (with a positive sign) in the food equation while the Paris dummy is significant (with a negative sign) in the transportation equation. On the other hand, the wife's age is significant (with a negative sign) in the clothing and the transportation equation.

We now turn to the estimated parameters of the sharing rule. Even if they are not significant at the $5 \%$ level, their standard deviation is relatively small. By comparison, Fortin and Lacroix (1997), who use the husband's labour supply to identify the sharing rule, yield standard deviations for structural parameters that are much greater. ${ }^{28}$ The estimates in Table 5 can be interpreted as follows. First, a one thousand franc increase in the wife's potential earnings (for a 160-hour week of work) decreases the wife's share by 281 francs. This means that the wife partially transfers her gains in utility to her husband. It can be shown, using (13), that the wife benefits from an increase in wage only if her monthly labour supply is greater than 45 hours. Second, a one thousand franc increase in the husband's earnings increases the wife's share by only 122 francs. That is, only a small part of the husband's earnings goes to the wife. This explains why the share coefficient in the wife's labour supply is unusually large (in absolute value) compared to estimates given by unitary models. Third, a one thousand franc increase in non-labour income increases the wife's share by 392 francs and the husband's share by 608 francs. Blundell et alii (2001) and Chiappori et alii (2002) provide estimates of the same order for the parameters of the sharing rule. These estimated parameters can also be used to test the hypothesis of pooling of the exogenous incomes. The latter implies that the husband's wage and non-labour income have the same impact on the sharing rule. The estimate of the difference $B-C$ is equal to -0.270 , with a standard deviation of 0.154 and a $p$-value of 0.079 . Therefore, the income pooling hypothesis is rejected at the $10 \%$ level (but not at the $5 \%$ level). This could explain why most parameters are not very precisely estimated, since the absence of income pooling is required for identification of the parameters, as shown by R1.

We finally consider the estimates of the wage elasticities (evaluated at the average values of the sample when the wife is unrationed on the labour market); they are presented in Table $5 .{ }^{29}$ To be precise, this table contains

\footnotetext{
${ }^{28}$ Blundell et alii (2001) obtain more precise estimates, but the sample they use contains about ten thousands households.

${ }^{29}$ Elasticities with respect to non-labour income are meaningless since non-labour income
} 


\begin{tabular}{lccccc}
\hline \hline & LAB & FOO & CLO & REC & TRA \\
\hline Wife's Wage & 2.704 & 0.321 & 0.518 & 0.653 & 2.358 \\
& $(0.401)$ & $(0.084)$ & $(0.171)$ & $(0.243)$ & $(0.532)$ \\
Husband's Wage & -0.712 & 0.378 & 0.512 & 0.839 & 0.138 \\
& $(0.213)$ & $(0.051)$ & $(0.102)$ & $(0.135)$ & $(0.228)$ \\
\hline \hline
\end{tabular}

Table 5: Income and wage elasticities (at the average point of the sample)

'reduced form' elasticities which mix the parameters of the Marshallian demand and supply functions and those of the sharing rule. For example, the elasticity $\varepsilon$ of the wife's labour supply with respect to the wife's wage is defined by

$$
\varepsilon=(\beta+\gamma A T) \cdot \frac{\bar{w}_{f h}}{\bar{L}_{f h}},
$$

where $\bar{w}_{f h}$ and $\bar{L}_{f h}$ are sample means. These elasticities have the advantage of being comparable with those of unitary models. First, for the labour supply, the husband's and wife's wage elasticities are respectively equal to -0.7 and 2.7. In terms of absolute value, they are about double the estimates obtained by Bourguignon and Magnac (1990). However, this is doubtlessly due to our specification with an upper bound for the wife's labour supply. ${ }^{30}$ Second, for the commodity demands, the elasticities are in line with intuition. They seem small because they are computed with respect to wages instead of total household income, as usual. The most remarkable fact here is the difference between the husband's and wife's wage elasticity of the demand for transportation expenditures. It probably reflects the fact that the demand for transportation dramatically depends on the employment status.

\section{Conclusion}

In this paper, we start from the assumption that the husband's hours of work are fixed at a legal maximum and we consider the wife's labour supply and household commodity demands in a unified framework. We first show

is not necessarily positive.

${ }^{30}$ In preliminary investigations, we estimated this model without such an upper bound. The elasticities obtained were very close to those in Bourguignon and Magnac (1990). 
that structural elements of the decision process can be identified with the observation of a single commodity demand function. Second, we generate a set of conditions that can be used to test the collective setting. Finally, we conclude with an empirical illustration using French data. These empirical results show that the structural parameters describing the intra-household decision process and the husband's behaviour are fairly well estimated.

The rigidity of the husband's labour supply is certainly a good approximation for numerous countries. However, the validity of our method for dealing with this rigidity, compared to that in Blundell et alii (2001), is an empirical issue. We conjecture, nevertheless, that the approach we advocate is preferable for investigating female labour supply in France, where the labour market is characterized by many job seekers.

Nevertheless, several theoretical extensions (e.g., fixed costs of participation, nonlinear income taxation, or involuntary unemployment) are necessary to properly assess the present setting. Above all, future research should concentrate on the stochastic specification and the functional form that we have adopted. Specifically, the linearity of the wife's labour supply is certainly a severe limitation. One serious problem here is that a more flexible specification does not allow us to recover a closed form for the shadow wages used to incorporate rationing in the model.

\section{A List of Proofs}

\section{A.1 Proof of Proposition 1}

If we differentiate the wife's labour supply function (3) with respect to $y$ and $w_{m}$ and eliminate $\lambda_{\rho_{f}}^{f}$, we obtain:

$$
L_{y}^{f} \cdot \rho_{w_{m}}=L_{w_{m}}^{f} \cdot \rho_{y} .
$$

Then we use this equation to differentiate the $n$th commodity demand function along the locus defined by $\mathrm{d} \rho=0$. We simplify and obtain the husband's

Engel curve: $\zeta_{\star \rho_{m}}^{m n}=\alpha^{n}$. If we differentiate this expression again with respect to $y, w_{m}$ and $w_{f}$, we obtain:

$$
\begin{aligned}
\zeta_{\star \rho_{m} \rho_{m}}^{m n} \cdot\left(1-\rho_{y}\right) & =\alpha_{y}^{n}, \\
\zeta_{\star \rho_{m} \rho_{m}}^{m n} \cdot\left(1-\rho_{w_{m}}\right) & =\alpha_{w_{m}}^{n}, \\
-\zeta_{\star \rho_{m} \rho_{m}}^{m n} \cdot \rho_{w_{f}} & =\alpha_{w_{f}}^{n} .
\end{aligned}
$$


Solving this system of partial differential equations with (14) yields:

$$
\begin{aligned}
& \rho_{w_{f}}=-\alpha_{w_{f}}^{n} \beta^{n}, \quad \rho_{w_{m}}=1-\alpha_{w_{m}}^{n} \beta^{n}, \quad \rho_{y}=1-\alpha_{y}^{n} \beta^{n} \text { and } \\
& \zeta_{\star \rho_{m} \rho_{m}}^{m n}=\left(\beta^{n}\right)^{-1} .
\end{aligned}
$$

To retrieve $\lambda_{\rho_{f}}^{f}$ and $\lambda_{w_{f}}^{f}$, we differentiate the wife's labour supply function with respect to $y, w_{m}$ and $w_{f}$, use (18), and rearrange to obtain :

$$
\lambda_{\rho_{f}}^{f}=\frac{L_{w_{m}}^{f}-L_{y}^{f}}{\left(\alpha_{w_{m}}^{n}-\alpha_{y}^{n}\right) \cdot \beta^{n}} \quad \text { and } \quad \lambda_{w_{f}}^{f}=L_{w_{f}}+\frac{L_{w_{m}}^{f}-L_{y}^{f}}{\left(\alpha_{w_{m}}^{n}-\alpha_{y}^{n}\right)} \cdot \alpha_{w_{f}}^{n} .
$$

Similarly, we can differentiate the $n$th commodity demand function with respect to $y, w_{m}$ and $w_{f}$, use (18), and rearrange to obtain:

$$
\zeta_{\rho_{f}}^{f n}=\frac{\alpha_{w_{m}}^{n} \cdot Q_{y}^{n}-\alpha_{y}^{n} \cdot Q_{w_{m}}^{n}}{\alpha_{w_{m}}^{n}-\alpha_{y}^{n}} \quad \text { and } \quad \zeta_{w_{f}}^{f n}=Q_{w_{f}}^{n}-\frac{Q_{w_{m}}^{n}-Q_{y}^{n}}{\alpha_{w_{m}}^{n}-\alpha_{y}^{n}} \cdot \alpha_{w_{f}}^{n} .
$$

Finally, knowing the sharing rule allows us to write down the wife's actual budget constraint and her preferences can be computed in the usual way.

\section{A.2 Proof of Proposition 2}

If we introduce the derivatives of the wife's labour supply function, given by (20), in the Slutsky Positivity condition, we obtain the first condition in the statement of the proposition. If we differentiate (19) with respect to $y, w_{m}$ and $w_{f}$, and simplify, we obtain the second condition. $\|$

\section{A.3 Proof of Proposition 3}

If we consider any pair of commodity demand functions, say $n_{1}$ and $n_{2}$, we have a corresponding pair of systems of equations (15)-(17). If we simplify, we obtain the condition in the statement of the proposition.

\section{A.4 Proof of Proposition 4}

The proof proceeds in stages. We prove that: (A) the sharing rule can be retrieved on the participation frontier, $(\mathrm{B})$ this identification can be extended on $\operatorname{int}(N)$, and $(\mathrm{C})$ testable restrictions are generated. 
A) Frontier solution: Along the participation frontier, by the continuity of the wife's labour supply function, we have the following identity:

$$
\lambda^{f}\left[\gamma\left(w_{m}, y\right), v\left(w_{m}, y\right)\right]=0,
$$

where $v\left(w_{m}, y\right)$ is infinitely differentiable. If we differentiate this identity with respect to $w_{m}$ and $y$ and eliminate $\lambda_{\rho_{f}}^{f}$ and $\lambda_{w_{f}}^{f}$, we obtain:

$$
\gamma_{y} \cdot v_{w_{m}}=\gamma_{w_{m}} \cdot v_{y}
$$

Then we use this expression and differentiate the $n$th commodity demand function along the direction $\mathrm{d} v=0$. We obtain the husband's Engel curve: $\zeta_{\star \rho_{m}}^{m n}=A^{n}$. We differentiate this expression again to obtain:

$$
\begin{aligned}
\zeta_{\star \rho_{m} \rho_{m}}^{m n} \cdot\left(1-v_{w_{m}}\right) & =A_{w_{m}}^{n}, \\
\zeta_{\star \rho_{m}}^{m n} \rho_{m} & \cdot\left(1-v_{y}\right)=A_{y}^{n} .
\end{aligned}
$$

Finally, using (21) and solving this system yields:

$$
\begin{aligned}
& v_{w_{m}}=1-A_{w_{m}}^{n} \cdot B^{n}, \quad v_{y}=1-A_{y}^{n} \cdot B^{n} \text { and } \\
& \zeta_{\star \rho_{m} \rho_{m}}^{m n}=B^{n} .
\end{aligned}
$$

These equations define the sharing rule up to an additive constant along the participation frontier.

B) Interior solution: We differentiate the $n$th commodity demand function with respect to $w_{m}, w_{f}$ and $y$ and eliminate $\zeta_{\star \rho_{m}}^{m n}$ and $\zeta_{\star \rho_{f}}^{f n}$ to obtain a partial differential equation in $\rho_{w_{f}}, \rho_{w_{m}}$ and $\rho_{y}$ :

$$
\left(Q_{w_{m}}^{n}-Q_{y}^{n}\right) \cdot \rho_{w_{f}}-Q_{w_{f}}^{n} \cdot \rho_{w_{m}}+Q_{w_{f}}^{n} \cdot \rho_{y}=0
$$

From standard theorems of the partial differential equation theory (e.g., John (1983)), the partial differential equation (25) together with the specification of the sharing rule on the boundary completely determines the wife's share $\rho$ for any $\left(w_{f}, w_{m}, y\right) \in N$, provided that a regularity condition is satisfied. First, let us remark that the partial differential equation (25) can be written as $u \cdot \nabla \rho=0$, where $\nabla \rho$ is the gradient of $\rho$ and $u$ is the vector $\left(Q_{w_{m}}^{n}-\right.$ $\left.Q_{y}^{n},-Q_{w_{f}}^{n}, Q_{w_{f}}^{n}\right)$. Now, the condition is that the vector $u$ is tangent to the participation frontier. Since the equation of this frontier is $w_{f}-\gamma\left(w_{m}, y\right)$ and given that, on the frontier, $Q$ coincides with $\hat{Q}^{n}$, this condition becomes: $\hat{Q}_{w_{m}}^{n} \neq \hat{Q}_{y}^{n}$. Formally, this result is local rather than global and additional conditions are required to identify the sharing rule on the entire set $N$.

C) Constraints: Differentiating (24) with respect to $y$ and $w_{m}$ and simplifying yields the condition in the statement of the proposition. $\|$ 


\section{B The Wage Equation}

The wage equation includes, among the explanatory variables, the wife's education (measured in years), the square and the cube of this variable, the wife's age, a cross-term of education and age, dummies for the wife's nationality (equal to one if it is different from French), for the region (Rural and Paris) and for households with a telephone and an indicator of the labour market tension. The latter is defined as:

$$
\log \left(\frac{\text { number of job offers by firms }}{\text { number of job demands by individuals }}\right)
$$

for each French department. Several variables in the right-hand side of the market wage regression are excluded from the empirical model of household behaviour. One important point is that, in order to obtain a greater precision, the wage equation is estimated with a large sample (1769 observations) which also includes households with more than one child. We see in Table 3 that all the parameters are very significant (with the expected sign). In principle, this permits identification of the effect of the wife's wage since some of the variables in the wage equation are excluded from the collective model in the main text. The coefficient of determination is, however, quite small. 


\begin{tabular}{lcc}
\hline \hline & Estimates & Std. Dev. \\
\hline Constant & 175.9 & 46.5 \\
Wife's Education & -41.9 & 15.7 \\
Wife's Education exp2 & 4.0 & 1.7 \\
Wife's Education exp3 x 10e ${ }^{-3}$ & -132.0 & 62.5 \\
Wife's Age & -10.2 & 2.5 \\
Wife's Education × Wife's Age x 10e ${ }^{-3}$ & 177.0 & 370.0 \\
Labour Market Tension & -4.7 & 1.6 \\
Wife's Nationality & -7.5 & 1.8 \\
Paris Region & 3.8 & 1.6 \\
Rural Region & -2.3 & 1.1 \\
Presence of a Telephone & 4.5 & 1.9 \\
Mill's Ratio & 4.0 & 1.7 \\
\hline $\mathrm{R}^{2}$ & 0.09 & \\
Number of Observations & 1769 & \\
\hline \hline
\end{tabular}

Table 6: Parameter Estimates of the Wage Equation

\section{References}

[1] Blundell R., P.-A. Chiappori, T. Magnac and C. Meghir (2001), "Collective Labour Supply: Heterogeneity and Nonparticipation", Working Paper 01-19, Institute for Fiscal Studies.

[2] Bourguignon F., M. Browning and P.-A. Chiappori (1995), "The Collective Approach to Household Behaviour", Working Paper 95-04, DELTA.

[3] Bourguignon F., M. Browning, P.-A. Chiappori and V. Lechene (1993), "Intra-household Allocation of Consumption: A Model and Some Evidence from French Data", Annales d'Economie et de Statistique 29: $137-156$.

[4] Bourguignon F. and T. Magnac (1990), "Labor Supply and Taxation in France", Journal of Human Resources 25: 358-389.

[5] Browning M., Bourguignon F., P.-A. Chiappori and V. Lechene (1994), "Income and Outcomes: A Structural Model of intra-household Allocation", Journal of Political Economy, 102: 1067-1096. 
[6] Browning M. and P.-A. Chiappori (1998), "Efficient Intra-household Allocations: A Genenral Characterization and Empirical Tests", Econometrica, 66: 1241-1278.

[7] Browning M. and C. Meghir (1991), "The Effects of Male and Female Labor Supply on Commodity Demands", Econometrica, 59: 925-51.

[8] Chiappori P.A. (1988), "Rational Household Labor Supply", Econometrica, 56: 63-90.

[9] Chiappori P.A. (1992), "Collective Labor Supply and Welfare", Journal of Political Economy, 100: 437-467.

[10] Chiappori P.A. (1997), "Introducing Household Production in Collective Models of Labor Supply", Journal of Political Economy, 105: 191-209.

[11] Chiappori P.A. and I. Ekeland (2002a), "The Micro Economics of Group Behavior: General Characterization", manuscript, University of Chicago.

[12] Chiappori P.A. and I. Ekeland (2002b), "The Micro Economics of Group Behavior: Identification", manuscript, University of Chicago.

[13] Chiappori P.-A., Fortin B. and G. Lacroix (2002), "Marriage Market, Divorce Legislation and Household Labour Supply", Journal of Political Economy, 110: 37-72.

[14] Donni O. (2003), "Collective Household Labor Supply: Nonparticipation and Income Taxation", Journal of Public Economics, 87: 1179-1198.

[15] Fong Y. and Zhang J. (2001), "The Identification of Unobservable Independent and Spousal Leisure", Journal of Political Economy, 109: 191-202.

[16] Fortin B. and G. Lacroix (1997), "A Test of the Unitary and Collective Models of Household Labour Supply", Economic Journal, 107: 933-955.

[17] Hausman J. (1981). "Labor Supply". In: Aaron H. and J. Pechman (eds), How Taxes Affect Economic behaviour, Washington D.C.: Brooking Institution. 
[18] John F. (1983), Partial Differential Equations, Springer Verlag, NewYork.

[19] Kooreman P. and Kapteyn A. (1986), "Estimation of Rationed and Unrationed Household Labour Supply Functions Using Flexible Functional Forms", Economic Journal, 96: 398-412.

[20] Laroque G. et Salanié B. (2002), "Labour Market Institutions ans Employment in France", Journal of Applied Econometrics, 17: 25-48.

[21] Lundberg S. et R Pollak (1996), "Bargaining and Distribution in Marriage", Journal of Economic Perspectives, 10: 139-158.

[22] Neary J.P. and K.W.S. Roberts (1980), "The Theory of Household Behaviour under Rationing", European Economic Review, 13: 25-42.

[23] Vermeulen F., 2002, "Collective Household Models: Principles and Main Results", Journal of Economic Surveys, 16: 533-564. 